\title{
Turnikesiz Unilateral Total Diz Artoplastisi Sonrası Kanama Kontrolünde Topikal Uygulanan Traneksamik Asitin Etkinliği
}

\section{The Efficacy of Topical Tranexamic Acid in Bleeding Control After Unilateral Total Knee Arthoplasty without Tourniquet}

\author{
Recep Kurnaz \\ Acıbadem Eskişehir Hastanesi, Ortopedi ve Travmatoloji Kliniği
}

\section{Öz}

Amaç: Total diz artroplastisi(TDA) sonrası kan kaybını, hemoglobin düsüklüğünü, kan transfüzyon ihtiyacını ve hastanede kalıs süresini azaltmak için traneksamik asit (TXA)' in topikal uygulamasındaki etkinliğini değerlendirmektir.

Gereç ve Yöntem: Total diz artroplastisi yapılan 40 hasta, $59-83$ yaşları arasından seçilmiştir. VAS 7' nin üzerinde, Ahlback evre 4-5 ve ASA 1. ve 2. grup olan hastalar çalışmaya dahil edilmiştir. Ameliyatlar aynı cerrah ve standart medial parapatellar artrotomi ile aynı marka implantlar kullanılarak yapılmıştır. Ameliyat boyunca turnike sadece sementleme aşamasında kullanılmıştır. Koagülopati, pulmoner emboli, akut myokard enferktüsü, beyin felci, kronik arter hastalığı hikayesi olanlar ve hemoglobin seviyesi $10 \mathrm{~g} / \mathrm{dl}$ nin altında olan hastalar calıșmaya alınmamıștır. Hastalar 2 gruba ayrıldı. Grup A' daki hastalara artrotomi kapatıldıktan sonra 4 ampül $250 \mathrm{mg} \% 10$ TXA salin ile seyreltilerek diz eklemine enjekte edildi. 2 saat boyunca dren kapalı tutuldu. Grup B' deki hastalarda TXA kullanılmadı. Drenler 48. Saat sonunda çekildi. Kan hemoglobin değerleri $8 \mathrm{~g} / \mathrm{dl}^{\prime}$ nin altına düşmedikçe kan transfüzyonu yapılmadı. Hastalar ko-morbiditeleri açısından da değerlendirmeye alındı.

Bulgular: 40 hastanın $8(\% 20)^{\prime}$ ine kan transfüzyonu yapıldı. Bunların $6(\% 75)^{\prime}$ SI TXA kullanılmayan Grup B' deki hastalar idi. Grup A' da sadece hastaların 2 (\%10)' sine kan trasfüzyonu yapıldı. Grup B' deki kan trasfüzyonu yapılan hastaların 1 tanesine 2 ünite kan replase edilmiştir. Ameliyat sonrası ilk 24 saatteki kan drenaj miktarlarına bakıldığında Grup A' da 232,5 cc, Grup B' de $407,75 \mathrm{cc}$ idi. 48. saat sonundaki toplam drenaj miktarına bakıldığında Grup

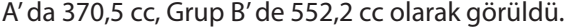

Ameliyat sırasında ortalama kanama miktarı Grup A' da 247,5 cc, Grup $B^{\prime}$ de 235 cc idi. Ameliyat öncesi ortalama hemoglobin değeri Grup $A^{\prime}$ da $13 \mathrm{~g} / \mathrm{dl}$ iken Grup B' de 12,75 g/dl idi. Ameliyattan sonraki 6. Saatte alınan hemoglobin degeri Grup A' da 11,7, Grup B' de $11 \mathrm{~g} / \mathrm{dl}$ olarak gözlendi. Ameliyat sonrası ilk 24. saatteki hemoglobin değerleri Grup A' da 11,07 iken Grup B' de 10,6 idi. 48. saatteki hemoglobin değerleri Grup A' da 10,3 iken Grup $B^{\prime}$ de 9,5 olarak gözlendi. Postop dönemdeki hemoglobin değişim seviyelerine ve drenaj miktarlarına bakıldığında TXA kullanılan grupta özellikle ilk 24. saatteki drenaj miktarında diğer gruba oranla önemli bir azalma olduğu gözlemlenmiştir.

Cıkarımlar:Total diz artroplastisinde traneksamik asit kullanımı postoperatif kanama miktarını anlamlı şekilde azaltır. TXA' nın intravenöz yerine eklem içi olarak uygulanmasıyla sistemik absorpsiyon azaltılabilir ve istenmeyen yan etkiler hafifletilebilir. Bu çalışmanın bulguları toplam kan kaybında ve hemoglobin seviyelerindeki azalmada bir düşüşs olduğunu ve dolayısıyla kan transfüzyonu ihtiyacını azalttığını göstermiştir.

Anahtar Kelimeler: Diz protezi, traneksamik asit, kanama kontrolü

\begin{abstract}
Aim: The aim of this study is to evaluate the efficacy of tranexamic acid (TXA) in the topical application of total knee arthroplasty (TKA) to reduce blood loss, low hemoglobin, need for blood transfusion and hospital stay.

Material and Method: Forty patients undergoing total knee arthroplasty were selected from 59-83 years of age. Patients with VAS 7 above Ahlback stage 4-5 and ASA group 1 and 2 were included in the study. The operations were performed using the same surgeon and standard medial parapatellar arthrotomy using the same brand implants. During the operation, the tourniquet was used only during cementation. Patients with a history of coagulopathy, pulmonary embolism, acute myocardial infarction, cerebral palsy, chronic arterial disease and patients with hemoglobin levels below 10 $\mathrm{g} / \mathrm{dl}$ were excluded from the study. The patients were divided into two groups. In Group A, 4 ampoules of 250 mg 10\% TXA saline were injected into the knee joint after arthrotomy was closed. The drain was kept closed for 2 hours. TXA was not used in Group B patients. Drains drained at 48 hours. Blood transfusion was not performed unless the blood hemoglobin values fell below $8 \mathrm{~g} / \mathrm{dl}$. The patients were also evaluated for their co-morbidities.

Results: Blood transfusion was performed in 8 (20\%) of 40 patients. Six (75\%) of these patients were in Group B without TXA. In Group A, only 2 (10\%) patients underwent blood transfusion. In Group B, 2 units of blood were replaced in 1 patient. Blood drainage levels in the first 24 hours were $232.5 \mathrm{cc}$ in Group A and $407.75 \mathrm{cc}$ in Group B. When the total drainage amount at the end of 48 th hour was examined, it was seen as $370.5 \mathrm{cc}$ in Group A and $552.2 \mathrm{cc}$ in Group B. The mean amount of bleeding during surgery was $247.5 \mathrm{cc}$ in Group A and $235 \mathrm{cc}$ in Group B. The mean preoperative hemoglobin level was $13 \mathrm{~g} / \mathrm{dl}$ in Group A and $12.75 \mathrm{~g} / \mathrm{dl}$ in Group B. Hemoglobin levels taken at the 6th postoperative hour were 11.7 in Group A and $11 \mathrm{~g} / \mathrm{dl}$ in Group B. Hemoglobin levels in the first 24 hours postoperatively were 11.07 in Group A and 10.6 in Group B. Hemoglobin values at the 48th hour were 10.3 in Group A and 9.5 in Group B. When the postoperative hemoglobin change levels and the amount of drainage were examined, it was observed that there was a significant decrease in the amount of drainage in the first 24 hours compared to the other group.

Conclusion:The use of tranexamic acid in total knee arthroplasty significantly reduces the amount of postoperative bleeding. Systemic absorption can be reduced and undesirable side effects can be alleviated by intra-articular administration of TXA instead of intravenous. The results of this study showed that there was a decrease in total blood loss and decrease in hemoglobin levels and thus reduced the need for blood transfusion.
\end{abstract}

Keywords: Knee replacement, tranexamic acid, bleeding control 


\section{GíRiş}

Total diz artroplastisi (TDA) ileri osteoartrit tedavisinde yaygın olarak kullanılan cerrahi prosedürlerdendir. ${ }^{[1]}$ Cerrahların bu ameliyatlar sonrasında bir çok komplikasyon ile karşılaşmaları muhtemeldir. Standart bir total diz artoplastisi sonrasında yaklaşık 1000-1500 cc kanama durumu bu komplikayonların önemli bir kısmını oluşturur. ${ }^{[2]}$ Bazı durumlarda hastaya kan transfüzyonu zorunlu hale gelmektedir. Son yıllarda kan transfüzyonundaki riskler açısından artan bir farkındalık meydana gelmiştir. ${ }^{[3,4]}$ Bu sorunun çözülmesi için klinisyenler sürekli bir çalışma içindedirler. ${ }^{[5,6]}$ Traneksamik asit (TXA)'in kullanımı da bu çözüm arayışının içindedir. Son çalışmalar, TXA'in kanamayı azaltmada etkili olduğunu desteklemektedir. ${ }^{[7,8]}$ Sentetik bir antifibrinolitik ajan olarak bilinen TXA, Lizin amino asitinden elde edilen 4 amino-metilsiklohekzenkarboksilik trans izomeridir. Bu formül plazmin ve plazminojen üzerindeki lizin bağlanma bölgelerini çekerek plazmin akivasyonunu inhibe eder ${ }^{[9]}$ Bu sayede pıhtı korunur, kanama riski ve yoğunluğu azalır. Bu çalışmanın amacı kan kaybını, hemoglobin düşüklüğünü, kan transfüzyon ihtiyacını ve hastanede kalış süresini azaltmak için TXA'in topikal uygulamasındaki etkinliğini değerlendirmek bu sayede komplikasyon riskinin azaltılmasını sağlamaktır.

\section{GEREÇ VE YÖNTEM}

Bu çalışma retrospektif kohort çalışmasıdır. Acıbadem Mehmet Ali Aydınlar Üniversitesi Tıbbı Araştırmalar Değerlendirme Kurulu tarafindan 19.12.2019 tarihinde 2019-20/10 Kasım sayılı karar numarası ile etik kurul onayı alınmıştır. 2014-Ocak 2019 tarihleri arasında primer diz osteoartriti tanısı ile total diz artroplastisi yapılan 40 hastadan oluşmaktadır. Çalışmaya alınan hastalar 59-83 yaşları arasından seçilmiştir. VAS (Visual Analog Pain Scale) 7'nin üzerinde, Ahlback radyolojik sınıflamasına göre evre 4-5 ve ASA (American Society of Anesthesiologists) sınıflandırmasına göre 1. ve 2. grup olan hastalar çalışmaya dahil edilmiştir. Ameliyatlar aynı cerrah tarafından Standart medial parapatellar artrotomi ile Genezis II, PS Knee System, Smith and Nephew marka implantlar kullanılarak yapılmış olup ameliyat sonrası antiembolik tedavi için 2 hafta boyunca 0,6 cc Düşük Molekül Ağırlıklı Heparin subkutan olarak uygulanmıştır. Ameliyat boyunca turnike sadece sementleme aşamasında kullanıldı.

Koagülopati, pulmoner emboli, akut myokard enferktüsü, beyin felci, kronik arter hastalığı hikayesi olanlar, ameliyattan 1 hafta öncesine kadar antikoagülan kullananlar ve hemoglobin seviyesi $10 \mathrm{~g} / \mathrm{dl}$ nin altında olan hastalar çalışmaya alınmamıştır. Hastalar 20'şerli olarak 2 gruba ayrıldı. Grup A'daki hastalara komponentlerin sementlenerek uygulanmasının ardından artrotomi kapatıldı. 4 ampül 250 mg \%10 traneksamik asit (TRANSAMINE, Actavis illaçları A.Ş.), $50 \mathrm{cc}$ izotonik \% 0,9 sodyum klorür Solüsyonu (i.E. Ulagay illaç Sanayii TÜRK A.Ş.) ile seyreltilerek diz ekleminin içine enjekte edildi. 2 saat boyunca dren kapalı tutuldu. Grup B'deki hastalarda TXA kullanılmadı. Drenler 48. Saat sonunda çekildi.
Her hastanın dreninden 24. ve 48. saatte gelen kan miktarı, ameliyat sonrası 6., 24. ve 48. saatlerdeki hemoglobin değerleri, kan transfüzyonu yapılıp yapılmadığı kayıt altına alındı.

Kan hemoglobin değerleri $8 \mathrm{~g} / \mathrm{dl}$ 'nin altına düşmedikçe kan transfüzyonu yapılmadı. Hastalar ko-morbiditeleri açısından da değerlendirmeye alındı. Ameliyat sonrası 24. saatte diz hareket açıklığı, düz bacak kaldırma egzersizleri başlanarak mobilize edildi. Ameliyat sonrası takiplerinde hiçbir hastada komplikasyon gözlenmemiştir.

\section{BULGULAR}

Araştırmaya alınan hastaların $25^{\prime} \mathrm{i}(\% 62,5)$ kadın, 15 'i $(\% 37,5)$ erkek idi. Grup A'da ortalama yaş 68,6, vücut kitle indexi: 31 , B grubunda ortalama yaş 67, vücut kitle indexi: 33 idi. 19 hastanın sağ, 21 hastanın sol dizi ameliyat edildi. Hastalar komorbiditesi açısından değerlendirildiklerinde Grup A'da 13 (\%65) hastada, Grup B'de 12 (\%60) hastada primer esansiyel hipertansiyon vardı. Diabetus mellitus ise Grup A'da 7 (\%35), Grup B'de 5 (\%25) hastada mevcuttu. Bunların dışında herhangi bir kronik hastalıkları yoktu.

İstatistiksel olarak değerlendirildiğinde iki grup arasında preop hemoglobin değerleri, intraop kanama miktarları ve demografik veriler açısından herhangi bir fark gözlenmemiş olup gruplar homojen olarak dağıtılmıştır (Tablo 1).

\begin{tabular}{lcc}
$\begin{array}{l}\text { Tablo 1. Preoperatif } \\
\text { miktarları }\end{array}$ & hemoglobin değerleri ve & intraoperatif kanama \\
& Preop hemoglobin & Intraop kanama \\
\hline Grup A & $13 \mathrm{~g} / \mathrm{dl}$ & $247,5 \mathrm{cc}$ \\
Grup B & $12,75 \mathrm{~g} / \mathrm{dl}$ & $235 \mathrm{cc}$ \\
\hline
\end{tabular}

Ameliyat sonrası ilk 24 saatteki kan drenaj miktarlarına bakıldığında Grup A'da 232,5 cc, Grup B'de 407,75 cc idi (Şekil 1). 48. saat sonundaki toplam drenaj miktarına bakıldığında Grup A'da 370,5 cc, Grup B'de 552,2 cc olarak görüldü (Şekil 2).

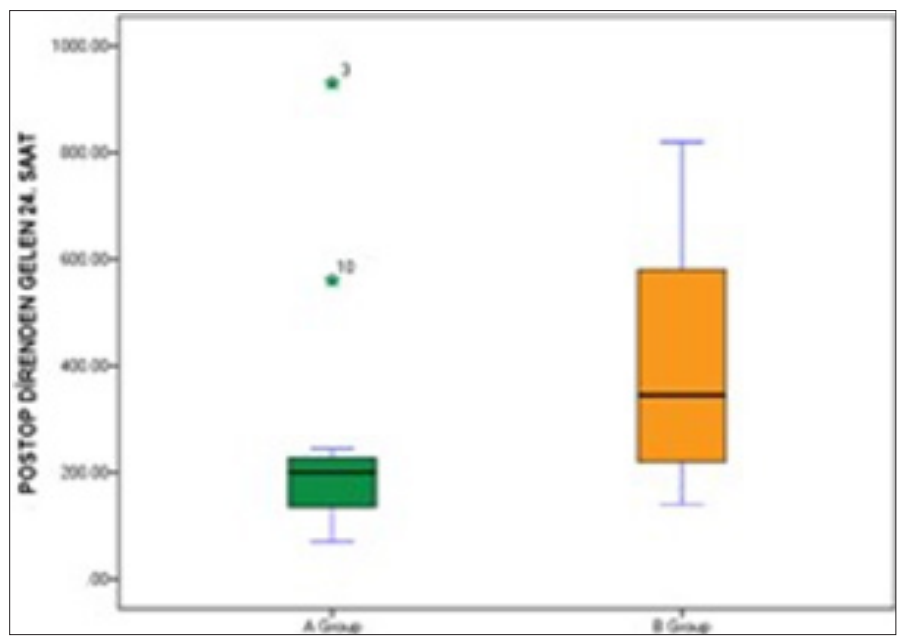

Şekil 1. Ameliyat sonrası 24 saatte drenden gelen kanama miktarları 


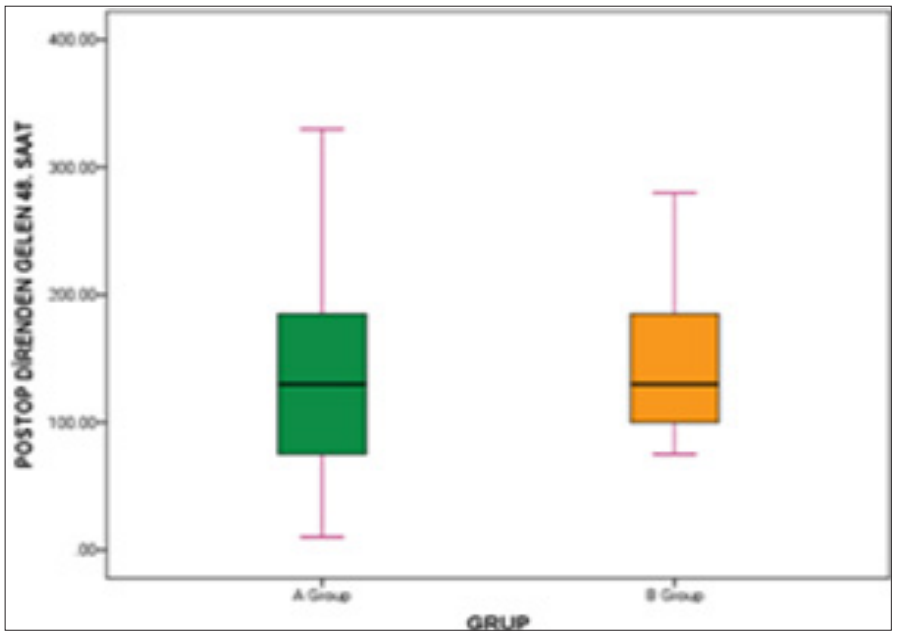

Şekil 2. Ameliyat sonrası 48 saatte drenden gelen kanama miktarları

Ameliyat sırasında ortalama kanama miktarı Grup A'da 247,5 cc, Grup B'de 235 cc idi. Ameliyat öncesi ortalama hemoglobin değeri Grup A'da $13 \mathrm{~g} / \mathrm{dl}$ iken Grup B'de 12,75 g/dl idi. Ameliyattan sonraki 6 . Saatte alınan hemoglobin değeri Grup A'da 11,7, Grup B'de $11 \mathrm{~g} / \mathrm{dl}$ olarak gözlendi. Ameliyat sonrası ilk 24. saatteki hemoglobin değerleri Grup A'da 11,07 iken Grup B'de 10,6 idi. 48. saatteki hemoglobin değerleri Grup A'da 10,3 iken Grup B'de 9,5 olarak gözlendi (Tablo 2).

\section{Tablo 2. Postoperatif hemoglobin değerleri}

\begin{tabular}{lccc} 
Hemoglobin (g/dl) & Postop 6. saat & Postop 24. saat & Postop 48.saat \\
\hline Grup A & 11,7 & 11,07 & 10,3 \\
Grup B & 11 & 10,6 & 9,5 \\
\hline
\end{tabular}

Total diz artroplastisi yapılan 40 hastanın 8 (\%20)'ine kan transfüzyonu yapıldı. Bunların 6 (\%75)'sı TXA kullanılmayan Grup B'deki hastalaridi.Grup A'da sadece hastaların 2 (\%10)'sine kan trasfüzyonu yapıldı. Grup B'deki kan trasfüzyonu yapılan hastaların 1 tanesine 2 ünite kan replase edilmiştir.

Postoperatif dönemdeki hemoglobin değişim seviyelerine ve drenaj miktarlarına bakıldığında TXA kullanılan grupta özellikle ilk 24. saatteki drenaj miktarında diğer gruba oranla önemli bir azalma olduğu gözlemlenmiştir.

\section{İstatistik}

Intraoperatif kanama miktarı A grup sıra ortalaması (rankı) 20,90 ve B grup sıra ortalaması (rankı) 20,10 olarak hesaplanmış ve $p=0,816>0,05$ olduğundan aralarında fark yoktur.

Postoperatif drenden 24. saat gelen A grup sıra oralaması (rankı) 14,55 ve B grup sıra ortalaması (rankı) 26,45 olarak hesaplanmış ve $p=0,001<0,05$ olduğundan aralarında fark vardır ve istatistiksel olarak anlamlıdır.

Postoperatif direnden 48. saat gelen A grup sıra oralaması (rankı) 19,85 ve B grup sıra ortalaması (rankı) 21,15 olarak hesaplanmış ve $p=0,724>0,05$ olduğundan aralarında fark yoktur.
Toplam direnden gelen A grup sıra oralaması( rankı) 15,10 ve B grup sıra ortalaması (rankı) 25,90 olarak hesaplanmış ve $p=0,003<0,05$ olduğundan aralarında fark vardır ve istatistiksel olarak anlamlıdır.

Postoperatif 1. gün hemoglobin değişkeninin A ve B grupları arasında eşit varyansa sahip olduğu testi sonucunda eşit varyanslı olduğu değişkenlikleri arasında fark olmadığı sonucuna ulaşılmıştır. Grup A ve B postoperatif 2. gün hemoglobin arasında fark istatistiksel olarak $\alpha=0,10$ göre anlamlıdır. (Mann-Whitney $\mathrm{U})(\mathrm{F}=3,046$ ve $\mathrm{p}=0,089<0,10)$ (Şekil 3).

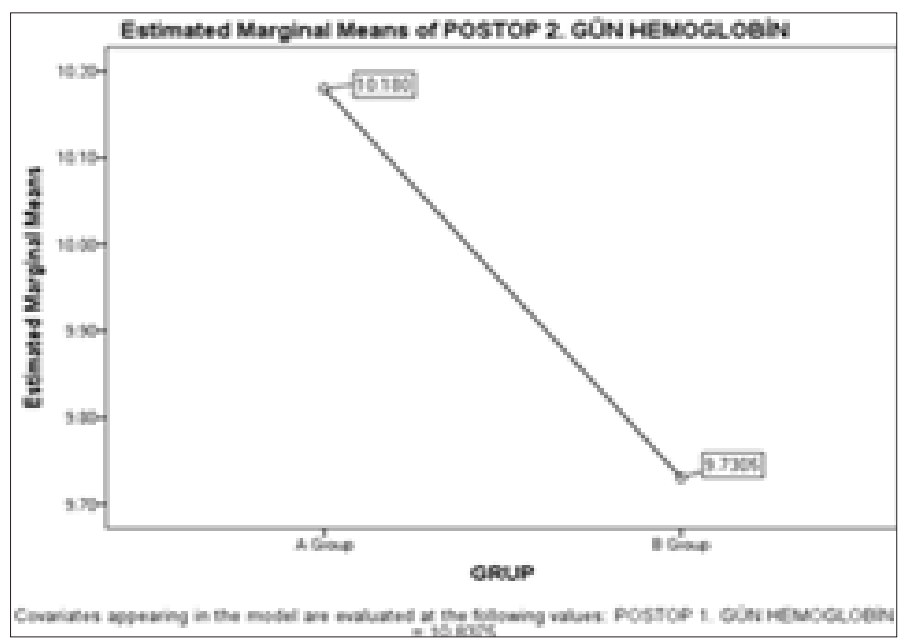

Şekil 3. Ameliyat sonrası 2. gün hemoglobinin gruplar arasındaki farkın incelemesi (Mann-Whitney U)

\section{TARTIŞMA}

Traneksamik asit, kan kaybını ve transfüzyonunu azaltmak için kullanılan etkili bir hemostatik ajandır. Bu çalışmada primer osteoartrit tanısı ile unilateral total diz artoplasitisi yapılan hastalarda kanama kontrolü açısından topikal uygulanan traneksamik asitin etkinliğini değerlendirdik.

Traneksamik asitin kullanımı oral, intravenöz, intramüsküler veya topikal olarak olabilir. Ortopedide en yaygın kullanımı intravenöz ve topikal olanıdır.

Roy ve ark. ${ }^{[10]}$ bizim çalışmamızdaki gibi eklem içine TA uygulayarak yaptığı çalışmada TXA ile tedavi edilen hastalarda kan transfüzyonunda azalma gözlemledi. Bu analiz için kullanılan parametreler hemoglobin seviyelerinin düşmesiydi. Sonuçlar kontrol grubunun TA grubundan altı kat daha fazla kan transfüzyonu aldığını gösterdi.

Aguilera ve ark. ${ }^{[11]}$ primer TDA geçiren 172 hastayı analiz etti. Tissucol $^{\circledast}$ (fibrinojen ve trombin) ile intavenöz (IV) TXA ve fibrin yapıştırıcısının etkinliğini karşılaştırdı. Bu çalışmanın sonuçları; TXA kullanan grupta kan kaybının düşük olduğunu gösterdi.

Intravenöz TXA uygulamasının topikal uygulama yöntemine kıyasla daha hızlı olma avantajı vardır. Benzer şekilde, ilacın kemik veya kas dokusu ile temasta etkisi olduğu literatürde net değildir. Ancak, TXA'in venöz tromboembolizm riskini artırma 
intimali vardır. Bu nedenle TXA'nın intravenöz yerine topikal olarak uygulanmasıyla sistemik absorpsiyon azaltılabilir ve istenmeyen yan etkiler hafifletilebilir. ${ }^{[12,13]}$

Böbrek yetmezliği, kalp ve serebrovasküler hastalıklar, DVT gibi durumlar TXA'in intravenöz kullanımında sorun yaratıp kullanımını kısıtlayabilir. ${ }^{[14-20]}$

Son çalışmalar TXA'in güvenli olabileceğini göstermiştir. ${ }^{[21,22]}$ Wong ve ark. ${ }^{[23]}$ IV ve topikal TXA uygulamasından sonra plazma konsantrasyonlarını ölçmüşler. Sonucunda topikal TXA uygulamasında plazma seviyelerini intravenöz uygulmaya göre $\% 70$ daha az olarak rapor etmişlerdir.

Patel ve ark. ${ }^{[24]}$ topikal TXA'nın güvenliği ve etkinliğini randomize edilmiş, çift kör bir prospektif çalışmada IV TXA ile karşılaştırmışlardır. Diğer yazarların raporları ile birlikte, bu çalışmalar, topikal TXA'nın, ilaç tedavisi için kontrendike olmayan hastalar arasında, IV TXA'e benzer bir güvenlik ve etkinlik profili sergilediğini göstermiştir. ${ }^{[25]}$

Lin ve ark. ${ }^{[26]}$ nın yaptığı çalışmada 120 hastayı randomize olarak üç gruba ayrmışlar. Bir grupa $20 \mathrm{~mL}$ serum fizyolojik içinde tek 1,0 g TXA dozu eklem kapsülü kapanmasından sonra (topikal grup); ikinci gruba cilt insizyonundan 15 dakika önce 1,0 g intravenöz TXA enjeksiyonu ardından lokal eklem kapsülü kapanmasından sonra 1,0 g'lık eklem içi uygulama ve üçüncü gruba ise sadece $20 \mathrm{~mL}$ normal salin solüsyonu vermişlerdir. Sonuçta beklendiği gibi, ortalama toplam kan kaybı hem topikal hem de kombine gruplarda plaseboya oranla daha düşük bulunmuştur. İki TXA grubu arasında ortalama toplam kan kaybını karşılaştııırken anlamlı bir fark olmadığını gözlemlemişlerdir.

2013 yılında Kim ve ark. ${ }^{[27]}$ tek taraflı ve iki taraflı total diz artroplastisinde TXA'in kan kaybını ve transfüzyon hızını azaltmadaki etkinliğini incelemek amacıyla bir çalışma yürütmüştür. Tek taraflı artroplasti uygulanan 180 hasta ve iki taraflı işlem geçirilen 146 hasta dahil edilmiştir. Bu çalışma, TXA'in toplam kan kaybını azalttığını, ancak kan transfüzyon hızı üzerindeki etkilerin, artroplastinin tipine göre değişebileceğini göstermiştir. Bilateral artroplastisi uygulanan hastalarda, tek taraflı artroplastisi uygulanan hastalara göre kan transfüzyonu oranında bir azalma olmuştur. Bu karmaşıklığa sebep olamamak için sadece unilateral TDA yapılan hastalar çalışmaya dahil edilmiştir. Kakar ve ark..$^{[1]}$ tek taraflı TDA geçiren 24 hasta ile bilateral ameliyat edilen 26 hastayı karşılaştırmışlar ve benzer sonuçlar göstermişlerdir. Bu çalışma aynı zamanda TXA'in, her iki grupta da ameliyat sonrası kan transfüzyonlarını azalttığı sonucuna varmıştır.

Farklı TXA uygulama yöntemleri arasındaki karşılaştırmanın, en etkili uygulama yöntemine ilişkin daha doğru bir sonuç elde etmek için araştııılması gerekir. Ancak, son çalışmalar sürekli olarak TXA'in TDA ameliyatlarında kanama miktarını ve kan transfüzyon ihtiyacını azalttığını doğrulamıştır. ${ }^{[28-30]}$

\section{SONUÇ}

Total diz artroplastisinde traneksamik asit kullanımı postoperatif kanama miktarını anlamlı şekilde azaltır. TXA'nın intravenöz yerine topikal olarak uygulanmasıyla sistemik absorpsiyon azaltılabilir ve istenmeyen yan etkiler hafifletilebilir. Bu çalışmanın bulguları toplam kan kaybında ve hemoglobin seviyelerindeki azalmada bir düşüş olduğunu ve dolayısıyla kan transfüzyonu ihtiyacını azalttığını göstermiştir.

\section{ETIK BEYANLAR}

Etik Kurul Onayı: Çalışma için Acıbadem Mehmet Ali Aydınlar Üniversitesi Tıbbı Araştırmalar Değerlendirme Kurulu tarafından 19.12.2019 tarihinde 2019-20/10 Kasım sayılı karar numarası ile etik kurul onayı alınmıştır.

Aydınlatılmış Onam: Çalışma retrospektif olarak dizayn edildiği için hastalardan aydınlatıımış onam alınmamıştır.

Hakem Değerlendirme Süreci: Harici çift kör hakem değerlendirmesi.

Çıkar Çatışması Durumu: Yazarlar bu çalışmada herhangi bir çıkara dayalı ilişki olmadığını beyan etmişlerdir.

Finansal Destek: Yazarlar bu çalışmada finansal destek almadıklarını beyan etmişlerdir.

Yazar Katkıları: Yazarların tümü; makalenin tasarımına, yürütülmesine, analizine katıldığını ve son sürümünü onayladıklarını beyan etmişlerdir.

\section{KAYNAKÇA}

1. Kakar, P.N., et al., Efficacy and Safety of Tranexamic Acid in Control of Bleeding Following TKR: A Randomized Clinical Trial. Indian J Anaesth, 2009. 53(6): p. 667-71.

2. Karam, J.A., et al., Evaluation of the efficacy and safety of tranexamic acid for reducing blood loss in bilateral total knee arthroplasty. J Arthroplasty, 2014. 29(3): p. 501-3

3. Lemaire, R., Strategies for blood management in orthopaedic and trauma surgery. J Bone Joint Surg Br, 2008. 90(9): p. 1128-36.

4. Levy O, M.U., Oran A, et al. The use of fibrin tissue adhesive to reduce blood loss and the need for blood transfusion after total knee arthroplasty. A prospective, randomized, multicenter study. J Bone Joint Surg Am 1999;81(11):1580-8.

5. Moonen, A.F., T.D. Neal, and P. Pilot, Peri-operative blood management in elective orthopaedic surgery. A critical review of the literature. Injury, 2006. 37 Suppl 5: p. S11-6.

6. Tobias, J.D., Strategies for minimizing blood loss in orthopedic surgery Semin Hematol, 2004. 41(1 Suppl 1): p. 145-56.

7. Carvalho Junior LH, C.C., Gonçalves MBJ, Rodrigues LCM, Lopes FL, et al. Complicações de curto prazo da artroplastia total do joelho: avaliação de 120 casos. Rev Bras Ortop. 2006;41(5):162-6.

8. Tan J, C.H., Liu Q, Chen C, Huang W. A meta-analysis of the effectiveness and safety of using tranexamic acid in primary unilateral total knee arthroplasty. J Surg Res. 2013;184(2):880-7.

9. Carvalho Junior LH, Castro CAC, Gonçalves MBJ, Rodrigues LCM, Lopes $\mathrm{FL}$, et al. Complicações de curto prazo da artroplastia total do joelho: avaliação de 120 casos. Rev Bras Ortop. 2006;41(5):162-6.

10. Roy SP, T.U., Dutta A, Jain SK, Nagi ON. Efficacy of intra-articular tranexamic acid in blood loss reduction following primary unilateral total knee arthroplasty. Knee Surg Sports Traumatol Arthrosc. 2012;20(12):2494-501. 
11. Aguilera X, M.-Z.M., Bosch A, Urrútia G, González JC, Jordan M, et al. Efficacy and safety of fibrin glue and tranexamic acid to prevent postoperative blood loss in total knee arthroplasty: a randomized controlled clinical trial. J Bone Joint Surg Am. 2013;95(22):2001-7.

12. Ipema HJ, Tanzi MG. Use of Topical Tranexamic Acid or Aminocaproic Acid to Prevent Bleeding After Major Surgical Procedures. Ann Pharmacother 2012;46:97-107. doi:10.1345/aph.1Q383.

13. Abrishami A, C.F., Wong J. Topical application of antifibrinolytic drugs for on-pump cardiac surgery: a systematic review and meta-analysis. Can J Anaesth 2009;56:202-12. doi:10.1007/ s12630-008-9038-x.

14. Endo Y, N.S., Miura A. Deep-vein thrombosis induced by tranexamic acid in idiopathic thrombocytopenic purpura. JAMA 1988;259(24):3561-3562.

15. Bruce-Brand R, D.R., Baker J, Harty J. Cerebrovascular infarction following bilateral total knee arthroplasty and tranexamic acid administration. Acta Orthop Belg 2013;79(3):351-354.

16. Sundström A, S.H., Kieler $H$, Alfredsson L. The risk of venous thromboembolism associated with the use of tranexamic acid and other drugs used to treat menorrhagia: a case-control study using the General Practice Research Database. BJOG 2009;116(1):91-97.

17. Salam A, K.C., Orhan O, Mak V. The great deception: tranexamic acid and extensive pulmonary emboli. BMJ Case Rep 2013;2013: pii: bcr2012007808.

18. Fodstad $\mathrm{H}$, Liliequist $\mathrm{B}$. Spontaneous thrombosis of ruptured intracranial aneurysms during treatment with tranexamic acid (AMCA). Report of three cases. Acta Neurochir (Wien) 1979;49; (3-4):129-144.

19. Lindoff C, R.G., Astedt B. Treatment with tranexamic acid during pregnancy, and the risk of thrombo-embolic complications. Thromb Haemost 1993;70(2):238-240.

20. Gupta PN, M.U., Sabin P, Vellappan P. Acute MI in a young hypertensive woman: could it be due to tranexamic acid? BMJ Case Rep 2013;2013:pii: bcr2013009979.

21. Duncan CM, Gillette BP, Jacob AK, Sierra RJ, Sanchez-Sotelo J, Smith HM. Venous thromboembolism and mortality associated with tranexamic acid use during total hip and knee arthroplasty. J Arthroplasty 2015;30(2):272276.

22. Whiting DR, Gillette BP, Duncan C, Smith H, Pagnano MW, Sierra RJ. Preliminary results suggest tranexamic acid is safe and effective in arthroplasty patients with severe comorbidities. Clin Orthop Relat Res 2014;472(1):66-72.

23. Wong J, A.A., El Beheiry $\mathrm{H}$, et al. Topical application of tranexamic acid reduces postoperative blood loss in total knee arthroplasty: a randomized, controlled trial. J Bone Joint Surg Am 2010;92(15):2503-2513.

24. Seo JG, Moon YW, Park SH, Kim SM, Ko KR. The comparative efficacies of intra-articular and IV tranexamic acid for reducing blood loss during total knee arthroplasty. Knee Surg Sports Traumatol Arthrosc 2013;21 (8):18691874.

25. Ishida K, Tsumura N, Kitagawa A, et al. Intra-articular injection of tranexamic acid reduces not only blood loss but also knee joint swelling after total knee arthroplasty. Int Orthop 2011;35(11): 1639-1645.

26. Lin SY, Chen CH, Fu YC, et al. The Efficacy of Combined Use of Intraarticular and Intravenous Tranexamic Acid on Reducing Blood Loss and Transfusion Rate in Total Knee Arthroplasty. J Arthroplasty 2015;30(5):776-80.

27. Kim TK, Chang CB, Kang YG, Seo ES, Lee JH, Yun JH, et al. Clinical value of tranexamic acid in unilateral and simultaneous bilateral TKAs under a contemporary blood-saving protocol: a randomized controlled trial. Knee Surg Sports Traumatol Arthrosc. 2014;22(8):1870-8.

28. Tan J, Chen H, Liu Q, Chen C, Huang W. A meta-analysis of the effectiveness and safety of using tranexamic acid in primary unilateral total knee arthroplasty. J Surg Res. 2013;184(2):880-7.

29. Oremus K. Tranexamic acid for the reduction of blood loss in total knee arthroplasty. Ann Transl Med. 2015;3(Suppl 1):S40.

30. Delanois RE, Mont MA. Does tranexamic acid reduce blood loss in total knee arthroplasty? Commentary on an article by
31.X. Aguilera, MD, et al.:"Efficacy and safety of fibrin glue and tranexamic acid to prevent postoperative blood loss in total knee arthroplasty. A randomized controlled clinical trial". J Bone Joint Surg Am. 2013;95(22):e179. 